\title{
Health-related direct-to-consumer genetic testing: a review of companies' policies with regard to genetic testing in minors
}

\author{
Pascal Borry · Heidi C. Howard · Karine Sénécal · \\ Denise Avard
}

Published online: 2 June 2009

(C) Springer Science+Business Media B.V. 2009

\begin{abstract}
More and more companies are advertising and selling genetic tests directly to consumers. Considering the ethical, legal, and psychological concerns surrounding genetic testing in minors, a study of companies' websites was performed in order to describe and analyze their policies with respect to this issue. Of the 29 companies analyzed, 13 did not provide any information about this matter, eight companies allowed genetic testing upon parental request, four companies stated that their website is not directed to children under 18 years, and four companies suggested that in order to be tested, applicants should have reached the age of legal majority. If private companies offer genetic tests which are also offered in a clinical setting, can they be expected to adhere to the existing clinical guidelines with regard to these tests? If so, a certain ambiguity exists. Many companies are emphasizing in their disclaimers that their services are not medical services and should not be used as a basis for making medical decisions. Nonetheless, it remains debatable whether genetic testing in minors would be appropriate in this context. In line with the Advisory Committee on Genetic Testing, the Human Genetics Commission addressed the problem of non-consensual testing and recommended not to supply genetic testing services directly to those under the age of 16 or to
\end{abstract}

P. Borry $(\bowtie) \cdot$ H. C. Howard

Centre for Biomedical Ethics and Law, Katholieke Universiteit Leuven, Kapucijnenvoer 35, Box 7001, 3000 Leuven, Belgium e-mail: Pascal.Borry@med.kuleuven.be

\section{K. Sénécal}

Centre de recherche en droit public, Université de Montréal, Montreal, QC, Canada

D. Avard

Centre for Genomics and Policy, McGill University,

Montreal, QC, Canada those not able to make a competent decision regarding testing.

Keywords Direct-to-consumer - Genetic testing · Children $\cdot$ Ethics $\cdot$ Advertising

\section{Introduction}

Advances in genetic knowledge and technologies have increased the possibilities of testing asymptomatic minors for late-onset diseases, carrier status or susceptibility to common complex disorders. These developments have raised concerns about the ethical, legal and psychological implications of performing genetic tests in healthy children and adolescents. Many professional associations have issued guidelines and position papers to address the issue of genetic testing in asymptomatic minors in a clinical context [1]. In general, these guidelines recommend that the availability of medical intervention is necessary before predictive genetic testing should be performed in asymptomatic minors. In order to protect the privacy and confidentiality of genetic information and the minor's right not to know [2], it has been advanced that testing asymptomatic children should be postponed until a minor can participate in the decision-making process [3]. It has also been argued that testing minors potentially creates serious social, emotional, psychosocial and educational consequences for the child and his family [4].

More and more companies are advertising and selling genetic tests directly to consumers (DTC) [5]. Such DTC genetic testing can be understood as including two related aspects: firstly, the advertising of genetic tests directly to consumers; and secondly, the direct access or ordering of genetic tests without the intermediate of a health care 
professional from the traditional health care system. The types of genetic tests being offered are extremely varied and include those that offer information regarding paternity, ancestry, health enhancement (nutrigenetics, dermatogenetics), drug response (pharmacogenetics), susceptibility testing for common complex genetic disorders (cardiovascular diseases, hereditary hemocromatosis, osteoporosis, type 2 diabetes...), as well as fetal gender tests (from 5 weeks on). Furthermore, some companies are offering "genetic profiles" which involve testing hundreds of thousands of single nucleotide polymorphisms (SNPs), the results of which are claimed to provide personal information regarding susceptibility to many different disorders. Finally, it should be noted, that some companies also offer genetic tests that are commonly offered in clinical genetics centres, such as those for monogenic disorders like cystic fibrosis and Tay-Sachs.

While proponents of DTC genetic testing argue that the benefits of offering such services will include increased access, and greater consumer autonomy, [6, 7] critics point to several potential risks associated with this type of service. Among others, concerns have been raised with regard to the clinical validity and utility of the genetic tests being offered [8]. Apprehensions have also been presented regarding the availability and quality of genetic counseling, the qualifications and impartiality of counselors, the effectiveness of telecounseling and the validity of the informed consent process [9]. Additional concerns revolve around the idea that the provision of genetic tests outside the health care system may consequently lead consumers to visit health care professionals (as a follow up to the genetic test results) and result in an overconsumption of health care services. Finally, the lack of regulatory control over DTC genetic testing services has also been raised as being an important problem $[10,11]$.

Above and beyond the worries already mentioned, an additional unease remains: what about the children? What protection is available when dealing with minors in the context of DTC genetic testing services? It has been reported that some companies offering direct-to-consumer genome scanning services accept requests to process samples from minors [12]. Since this earlier contribution only analyzed five companies offering specific services (testing of a large number of SNPs, or genome scans), we provide herein, a more complete overview of the current policies regarding genetic testing in minors based on the information found on companies' websites.

\section{Methods}

The companies included in this analysis were obtained from a list published by the Genetics and Public Policy Center (Johns Hopkins University, November 2008) [13]. Thirty-five companies were included in this list, and were considered companies which offer "tests and test interpretation directly to consumers rather than through the traditional model of health care provider-offered genetic tests." [13]. Only companies offering health-related genetic tests that are not explicitly prenatal in nature were included in the analysis. Companies exclusively offering paternity, genealogy, or ancestry tests, as well as those offering DNA matching services (for the main purpose of finding a romantic partner) were excluded. The entire content of the companies' websites, including their consent forms, terms of services and privacy policy statements were analyzed in December 2008. All statements or policies found on the websites and addressing the issue of genetic testing in minors were listed, analyzed and categorized. Every website was reviewed independently by PB and $\mathrm{HCH}$.

\section{Results}

Websites from 29 companies (Table 1) were analyzed. Of the original set of 35 companies considered, one company had ceased its activities (Smart Genetics), one company offers only fetal gender testing (ACU-gen Biolabs), one company offers only prenatal diagnostic services (Niagen) and two companies offer only DNA matching services (GenePartner, Scientific Match). Health Tests Direct was also excluded from the analysis because the company sends consumers to a 'blood draw center' located as close as possible to the consumer's home, and the different types of tests offered change depending on each "blood draw center".

The information presented on companies' websites regarding the possibility of performing genetic tests in minors, was grouped into one of four categories: (1) companies which do not provide any information on this issue (Table 1 group A); (2) companies which state that they will allow genetic testing upon parental request and/or authorization (Table 1 group B, and Table 2); (3) companies which make clear that their website is not directed towards minors but are not explicit about whether they would refuse testing in minors upon parental request (Table 1 group C, and Table 3); and (4) companies which provide information that suggests that their tests are not directed toward minors (Table 1 group D, and Table 4).

Companies allowing genetic testing in minors upon parental request and/or authorization

There are eight companies $(28 \% ; 8 / 29)$ that allow genetic testing in minors upon parental request (Table 1 group $B$ and Table 2). Although some companies (e.g. 23andme, DNA direct) do acknowledge that their services are not "designed or intended to attract children under the age of 13 ", in the 
Table 1 List of companies and their genetic tests offered

Company DNA tests offered

Group A: companies that do not provide information on genetic testing in minors

1. DNA dimensions (USA, www.detroitdna.com)

2. DNA traits (USA, www.dnatraits.com)

3. GeneLink Biosciences (USA,

4. G-Nostics (UK, www.g-nostics.com)

5. Graceful Earth (USA, www.gracefulearth.com)

6. Health Check USA (USA, www.healthcheckusa.com)

7. Holistic Health consultants (USA, www.holisticheal.com)

8. Knome (USA, www.knome.com)

9. My Genome (USA, www.mygenome.com)

10. New Hope Medical (USA, www.newhopemedical.org)

11. Proactive Genomics (USA, www.proactivegenomics.com/)

12. Interleukin Genetics (USA, www.ilgenetics.com)

13. Sciona (USA, www.sciona.com; www.mycellf.com) www.genelinkbio.com)

Alzheimer

Ashkenazi Jews Genetic Disease Panel (25 disorders); Clotting Disorders Panel; Sickle Cell and $\beta$-Thalassemia Panel; All tests from the panels can be purchased individually

DNA Based Assessments (Oxidative Stress Assessment, Comprehensive Cardiovascular Assessment, Bone Health Assessment (Osteo-Health), Healthy Aging Assessment, Dermagenetics ${ }^{\mathrm{TM}}$ Skin Health Assessment, CoQ10 Efficiency Assessment, Lipid Metabolism and Metabolic Syndrome Assessment, Dermagenetics Skin Health); Dermagenetics Skin Care System $^{\mathrm{TM}}$, Nutragenetics Nutritional Care System ${ }^{\mathrm{TM}}$ NicoTest $^{\mathrm{TM}}$

Alzheimer

Celiac disease DNA test; Combined Factor V Leiden with Prothrombin (Factor II) DNA Test; Factor V Leiden DNA Test; Factor V Leiden DNA Test; Hereditary

Hemochromatosis; Prothrombin (factor II) DNA Test

Comprehensive Methylation Panel with Methylation Pathway Analysis

Whole-genome sequencing and comprehensive analysis services for individuals

Alzheimer's disease, Cardiovascular disease, Thrombosis, Pregnancy risk, Osteoporosis, Drug sensitivities

12, 19 and 25 SNP panel

Focus $5^{\mathrm{TM}}$ Prostate Cancer Risk Test

Periodontal disease (gum disease), Gensona ${ }^{\mathrm{TM}}$ Heart Health, Gensona ${ }^{\mathrm{TM}}$ General Nutrition Test

Mycellf DNA Fitness Program, Mycellf DNA Nutrition Program

Group B: companies allowing genetic testing in minors upon parental request and/or authorization

1. 23andme (USA, www.23andme.com)

2. Consumer genetics (USA, www.consumergenetics.com)

Personal genotypes services

Asthma Drug Response Test: ß16AsthmaGEN ${ }^{\mathrm{TM}}$, Alcohol Metabolism DNA Testing: WineGEN $^{\mathrm{TM}}$, Caffeine Metabolism DNA Testing: CaffeineGEN ${ }^{\mathrm{TM}}$

decodeme.com Genetic Scan

Alpha-1 Antitrypsin Deficiency, Ashkenazi Jewish Carrier Panel, Blood clotting disorders (Factor V Leiden), Breast and Ovarian Cancer, Colon cancer screening, Cystic Fibrosis, Haemochromatosis, Hereditary colon cancer, Infertility, Recurrent pregnancy loss, Drug Response Testing (CYP2D6, CYP2C9, CYP2C19); Tamoxifen (2D6 genes); Warfarin (VKORC1 and CYP2C9

Gene Test for Gluten Sensitivity/Celiac Sprue

Asthma, Dyspepsia, Eczema, gluten sensitivity, lactose intolerance, mold allergies, norwalk virus, stroke (after cardiac surgery), post-operative cognitive dysfunction, percentage body fat, obesity, learning and memory, hemochromatosis, increased drug addiction, alcohol and nicotine response, alcohol metabolism, Warfarin (CYP2C9 gene)

Bipolar disorder and major depression, selective serotonin reuptake inhibitors

Genomic Profiling Service

8. Seqwright (USA, www.seqwright.com)

Group C: companies making clear that their website is not directed to minors, but don't explicitly say that they would refuse genetic testing in minors on parental request

1. Biomarker Pharmaceuticals (USA,

Gene Essence Report www.geneessence.com)

2. CyGene Direct (USA, www.cygenedirect.com)
Bone Health Genetics (Osteoporosis DNA Analysis), Vision Health Genetics (Glaucoma \& Macular Degeneration DNA Analysis), Blood Clotting Genetics (Thrombosis DNA Analysis), StrokeScan DNA Analysis, Metabolic Health Assessment (Metabolic Health Assessment DNA Analysis) 
Table 1 continued

\begin{tabular}{|c|c|}
\hline Company & DNA tests offered \\
\hline $\begin{array}{l}\text { 3. Salugen-DNA services of America } \\
\text { (USA, www.salugen.com; } \\
\text { www.genotrim.com) }\end{array}$ & Genotrim (obesity), Haveos (addiction), Spagen (nutrigenomic) \\
\hline 4. MediChecks (UK, www.medichecks.com & Various genetic tests for monogenetic and complex disorders, as well as other blood tests \\
\hline \multicolumn{2}{|c|}{ Group D: companies suggesting that in order to be tested, applicants should be 18 years of age or older } \\
\hline 1. Navigenics (USA, www.navigenics.com) & 'Navigenics Health Compass' \\
\hline 2. Genelex (USA, www.healthanddna.com) & $\begin{array}{l}\text { Nutritional Genetic Profile with a nutritionist consultation, Celiac Disease DNA Test, } \\
\text { Hemochromatosis DNA Test, Periodontal Disease DNA Test, Narcolepsy DNA Test); } \\
\text { CYP2D6 (cytochrome P450 2D6); CYP2C9 (cytochrome P450 2C9); CYP2C19 } \\
\text { (cytochrome P450 2C19); CYP1A2 (cytochrome P450 1A2); NAT2 ( } N \text {-acetyltransferase } \\
\text { 2); DPD (dihydropyrimidine dehydrogenase); UGT1A1 (UDP-glucuronosyltransferase); } \\
\text { 5HTT (Serotonin Transporter) }\end{array}$ \\
\hline 3. Inneova (Canada, www.inneova.com) & $\begin{array}{l}\text { Anti-aging test, Hormone replacement therapy management, Weight control, optimal } \\
\text { health test, vascular risk test, cancer risk test, dermatogenetic test, Pharmacogenomics } \\
\text { test, Whole DNA Sequencing (through Knome) }\end{array}$ \\
\hline 4. Suracell (USA, www.suracell.com) & Personal DNA analysis \\
\hline
\end{tabular}

same breath, some also allow parents to sign a consent form for their child (as in the case of Consumer Genetics and Seqwright), order and set up an account for their services on behalf of his or her child (as in the case of 23andme), or fill in risk assessment questionnaires, and order genetic tests (as in the case of DNAdirect). Four companies (23andme, DNA direct, iGenix-Q Trait, Psynomics) underline in similar words that the parent or guardian assumes full responsibility for ensuring that the information that he/she provides about his or her child is kept secure and that the information submitted is accurate. None of the eight companies accept test requests directly from adolescents without the supervision of a parent. For example iGenix states that their "services are not intended for unsupervised use by children under the age of $18 . "$

Companies which make clear that their website is not directed towards minors

Four companies of the 29 (14\%) (Table 1 group C, and Table 3) make clear that their website is not directed to children under 18 years of age. Cygene Direct describes that "...this website is not intended for, or designed to attract, individuals under the age of 18." However, it remains unclear whether these companies would refuse to perform genetic tests upon parental request.

Companies suggesting that in order to be tested, applicants should be 18 years of age or older

Four companies $(14 \% ; 4 / 29)$ compose group D (Table 1 group D, and Table 4); information on their websites suggests that test applicants should have reached the age of legal majority in order to be tested. For example, Suracell states that "when an individual requests participation in the Suracell Program, they must certify that they are 18 years of age or older"; Inneova asks applicants to confirm that "I am an adult over the age of 18 years (or over the age of consent in jurisdiction where such age is higher than 18 years)". Navigenics also states that "Given the ethical, privacy and informed consent considerations regarding genetic testing of minors for predisposition or carrier status of adult-onset genetic disorders, Navigenics does not knowlingly collect or use information from minors under the age of 18."

\section{Discussion}

Our findings suggest that certain companies appear to have an awareness of some of the social, ethical and legal issues pertaining to genetic testing in minors. However, our results also demonstrate that other companies challenge the ethical framework of protecting children as they are willing to provide genetic testing in a pediatric population. Because of the sensitive nature of genetic information, the right to autonomous decision making and self-determination, confidentiality and privacy issues, we feel it is important to take specific notice of direct-to-consumer genetic testing issues for minors.

Clinical guidelines focusing on genetic testing in minors have emphasized that the best interest of the child is paramount and that perceived benefits and risks of testing must be carefully weighed when considering a genetic test in minors. In the context of a genetic test for a late onset disorder (e.g. BRCA), testing has only been recommended when "established, effective, and important medical 
Table 2 Group B. List of companies allowing genetic testing in minors upon parental request and/or authorization

\begin{tabular}{ll}
\hline Company & Policy \\
\hline 1. 23andme & You represent that you are eighteen (18) years of age or older. You are guaranteeing that the sample you provide is \\
& your saliva; if you are completing this consent form on behalf of a person for whom you have legal authorization, \\
& you are confirming that the sample provided will be the sample of that person." (Consent and legal agreement, \\
& https://www.23andme.com/about/consent, accessed 10 January 2009) \\
" 23 andme is committed to protecting the privacy of children, as well as adults. Neither 23 andme nor any of its \\
services are designed or intended to attract children under the age or 13. A parent or guardian, however, may \\
order and set up an account for our services on behalf of his or her child. The parent or guardian assumes full \\
responsibility for ensuring that the information that he/she provides to 23andme about his or her child is kept \\
secure and that the information submitted is accurate." (Privacy statement, \\
https://www.23andme.com/about/privacy, accessed 10 January 2009)
\end{tabular}

2. Consumer genetics

"Signature (Parent or Guardian if patient is a minor" for Asthma Drug Response Test. (no information for other tests)

3. Decode

4. DNA direct

5. Enterolab

6. iGenix-Q Trait

7. Psynomics

8. Seqwright

Informed consent form, http://www.consumergenetics.com/pdfs/Asthma-Brochure.pdf, accessed 10 January 2009

"Either you are the owner of the sample or have full authority of the owner or subject of the sample to submit the sample for processing." (The deCODEme concept, http://www.decodeme.com/index/about_concept, accessed 10 January 2009)

"We are committed to protecting the privacy of children. Neither DNA Direct nor any of its services are designed or intended to attract children under the age of 13. We do not collect Personally Identifiable Information from any person we actually know is under the age of 13. A parent or guardian, however, may do any of the following things on behalf of his or her child: (a) complete a risk assessment questionnaire; (b) register to save partiallycompleted risk assessment questionnaires; (c) save partially-completed risk assessment questionnaires; (d) order genetic tests; and (e) register to receive promotional communications. The parent or guardian assumes full responsibility for ensuring that the information that it provides to DNA Direct about his or her child is kept secure and that the information submitted is accurate."

Privacy Policy, http://www.dnadirect.com/patients/about/privacy.jsp, accessed 10 January 2009

"Tests for persons under the age of 18 must be ordered by a parent or legal guardian."

Instructions for completion of a successful order, https://www.enterolab.com/CustomerPages/Createorder1.aspx, accessed 10 January 2009

"The iGenix services are not intended for unsupervised use by children under the age of 18. A parent or legal guardian, however, may order and set up an account for our services on behalf of his or her child. The parent or guardian assumes full responsibility for ensuring that the information that he/she provides to iGenix about his or her child is kept secure and that the information submitted is accurate."

Privacy Policy, http://www.qtrait.com/privacy_policy, accessed 10 January 2009

"We are committed to protecting the privacy of children. Neither Psynomics nor any of its services are designed or intended to attract children under the age of 18. We do not collect Personally Identifiable Information from any person we actually know is under the age of 14. A parent or guardian, however, may do any of the following things on behalf of his or her child, if over the age of 13 and under the age of 18: (a) order genetic tests; and (b) register to receive communications. The parent or guardian assumes full responsibility for ensuring that the information that it provides to Psynomics about his or her child is kept secure and that the information submitted is accurate."

Privacy Policy, https://www.psynomics.com/pdf/privacy_policy.pdf, accessed 10 January 2009

"I am at least 18 years of age OR I am the legal guardian of the client (if the client is younger than 18 years old or unable to sign below)"

Personal information and acknowledgment form, https://gps.seqwright.com/orderform.php, accessed 10 January 2009 treatment" [14] can be offered or when testing "provides scope for treatment which to any essential degree prevents, defers or alleviates the outbreak of disease or the consequences of the outbreak of disease" [15]. The rationale behind this option is that predictive and presymptomatic testing for adult-onset disease "should be delayed until the person is old enough to make an informed choice" [16]. The same notion applies to carrier testing, where it has been advanced that "For carrier status for conditions that will be important only in reproductive decision making, testing of children should be discouraged until the child is able to participate fully in the decision to be tested" [17]. In the case of presymptomatic and predictive genetic testing for conditions which manifest in childhood, the current policy depends on whether this condition can be effectively treated or prevented. If preventive or therapeutic measures are available, "there are good reasons to comply or to actively bring up the possibility of a test. 
Table 3 Group C. List of companies which make clear that their website is not directed to minors, but donot explicitly say that they would refuse genetic testing in minors on parental request

Company Policy

1. Biomarker Pharmaceuticals

"This site is not directed to children under 18 . We do not knowlingly collect personally identifiable information from children under 18. If a parent or guardian becomes aware that his or child has provided us with any personal information without their consent, he or she would notify us immediately. If we become aware that a child under 18 has provided us with personal information we will delete such information from our files."

2. CyGene Direct

Privacy policy, http://www.geneessence.com/our-labs/privacy-policy.html, accessed 10 January 2009

"You should also be aware that this website is not intended for, or designed to attract, individuals under the age of 18 . We do not collect personally identifiable information from any individual we actually know is an individual under the age of 18 . We also ask that they not use this website or provide us with any information."

Privacy Policy, http://www.dnatestnow.com/t-privacy.aspx, accessed 10 January 2009

3. Salugen-DNA services of America The Salugen website is intended for use by adults only. Minors under the age of 18 years may not use this website.

Terms \& Conditions http://www.salugen.com/terms-conditions.html, accessed 10 January 2009

5. MediChecks

"Children should always get permission from their parents before sending any information about themselves (such as their names, e-mail addresses, and phone numbers) over the internet, to us or to anyone else. We won't knowlingly allow anyone under 18 to register with our site."

Privacy Policy, http://www.medichecks.com/privacy.cfm, accessed 10 January 2009

Table 4 Group D. List of companies suggesting that in order to be tested, applicants should be 18 years of age or older

\begin{tabular}{|c|c|}
\hline Company & Policy \\
\hline \multirow[t]{2}{*}{ 1. Navigenics } & $\begin{array}{l}\text { "This website is not directed toward minors under } 18 \text { years of age. Given the ethical, privacy and informed consent } \\
\text { considerations regarding genetic testing of minors for predisposition or carrier status of adult-onset genetic disorders, } \\
\text { Navigenics does not knowlingly collect or use information from minors under the age of 18." }\end{array}$ \\
\hline & Privacy Policy, http://www.navigenics.com/policies/Privacy/, accessed 10 January 2009 \\
\hline \multirow[t]{2}{*}{ 2. Genelex } & "This test is only available to people 18 or older." for Nutritional Genetic Profile. (No information for other tests) \\
\hline & $\begin{array}{l}\text { Order Nutritional genetic testing, http://www.healthanddna.com/professional/nutrigenetics.html, accessed } 10 \text { January } \\
2009\end{array}$ \\
\hline \multirow[t]{2}{*}{ 3. Inneova } & $\begin{array}{l}\text { "I confirm that I am an adult over the age of } 18 \text { years (or over the age of consent in jurisdictions where such age is } \\
\text { higher than } 18 \text { years), that I enter into this Agreement voluntarily, and that I am legally entitled to do so." }\end{array}$ \\
\hline & $\begin{array}{l}\text { Terms \& Conditions and Statement of Consent, http://www.inneova.com/contenu.php?page=terms.php, accessed } 10 \\
\text { January } 2009\end{array}$ \\
\hline \multirow[t]{2}{*}{ 4. Suracell } & $\begin{array}{l}\text { When an individual requests participation in the Suracell Program, they must first certify that they are } 18 \text { years of age } \\
\text { or older, and that they consent to supply Suracell with personal health information, such as their specimens and } \\
\text { answers to the Suracell Environmental and Lifestyle Questionnaire. }\end{array}$ \\
\hline & Privacy Policy, http://www.suracell.com/privacy.aspx, accessed 10 January 2009 \\
\hline
\end{tabular}

However, if the preventive and therapeutic measures will be deferred to a later time, the justification for immediate testing is less compelling and careful, supportive counselling will often be appropriate whether or not testing happens at that time"[18]. When no treatment or prevention is available, "there are both benefits and risks, and usually neither the benefits nor the risks completely outweigh each other. Genetic testing could be considered if this would be to the psychological or social benefit of the child and his family" [18].

Since the companies studied offer a wide variety of tests, many of which have yet to be offered through the traditional health care system, it could be said that these companies offer services that are not necessarily included in the scope of the existing clinical guidelines regarding minors. However, if we only consider tests already accepted in a clinical setting, can we expect these companies to follow established guidelines? According to DNA Direct's website "a parent or guardian (...) may do any of the following things on behalf of his or her child: (...) (d) order genetic tests" (Table 2). The company adds that in this case "The parent or guardian assumes full responsibility for ensuring that the information that it provides to DNA Direct about his or her child is kept secure and that 
the information submitted is accurate" (Table 2). If they are indeed strictly following this policy, it would conflict with existing professional guidelines as they are providing, among other tests, genetic tests for breast cancer (BRCA1, BRCA2). This being said, due to the limitations of a web based analysis, it is impossible to ascertain exactly how this company would react if a parent were to order BRCA testing for their child in reality. After all, this company does require that consumers contact a company counselor before ordering BRCA testing, and therefore, it is possible that a parental request for a child to be tested could be denied at this stage regardless of what is written on their website. Moreover, DNA Direct underlines that they are operating "according to the standards and guidelines of the National Society of Genetic Counselors and the American College of Medical Genetics, using board-certified personnel under the supervision and authorization of a physician" [19]. Both professional bodies hold a clear position on testing in minors. The American College of Medical Genetics states that "If the medical or psychosocial benefits of a genetic test will not accrue until adulthood, as in the case of carrier status or adult-onset diseases, genetic testing generally should be deferred. Exceptions to this principle might occur when the adolescent meets conditions of competence, voluntariness, and adequate understanding of information" [20]. The National Society of Genetic Counselors states that when possible, as in the case of late-onset disorders, "the child should be involved in the decision about whether or not to be tested" [21]. This type of ambiguity concerning which policy is being followed should be reduced to a minimum and private companies offering genetic tests directly to consumers should be explicit about which standards they are adhering to, particularly with respect to testing in minors.

As alluded to previously, in view of the major ethical considerations that surround predictive genetic testing and carrier testing in minors, one could question whether the same guidelines apply for tests that are described by companies as not being for the purpose of preventing, diagnosing or treating medical conditions. It is interesting to note that many companies offering DTC genetic testing declare that their services are not clinical services and should not be used as a basis for making medical decisions. For example, Consumer Genetics writes in its Authorization and Disclosure form that "all materials and products provided by Consumer Genetics, Inc. are provided for informational purposes only and are not by themselves intended for diagnosis or treatment of any disease or disorder" [22]. The privacy policy found on iGenix, Inc's website describes that its "service is not a test or kit designed to diagnose disease or medical conditions. Information you receive from the iGenix, Inc. service is not intended to be medical advice" [23]. Likewise, 23andme emphasizes in its Terms of Service that their "service content is not to be used, and is not intended to be used, by you or any other person to diagnose, cure, treat, mitigate or prevent a disease or other impairment or condition, or to ascertain your health" [24].

Various companies state that the predictive value of their genetic tests is insufficient as a useful basis for personalized nutritional and lifestyle recommendations. It remains, however, a possibility that consumers will overestimate the predictive value of the genetic tests [25]. Knowledge of an increased disease risk may affect the relationship between parents and children, and engender in the parents a sense of responsibility both for the disorder itself and for protecting the infant from its impact [26]. Excessive attention to genetic risk information could also decrease the attention to non-genetic factors in disease development and lead to an overestimation of (non-validated) risk information [27].

Moreover, by accepting children's samples submitted by their parents, some companies are neglecting some of their own positions with regard to the sensitive and private character of genetic information. SeqWright states that "your genetic information is extremely sensitive. In fact, it may be the most sensitive information there is and as new discoveries are made, and more is learned about what your genes say about you, this information is likely to become evermore sensitive over time" [28]. deCODE claimed that "the only people who should be able to see your genetic information are you and those with whom you choose to share it" [29]. Contrary to the latter two companies, which do provide testing in children, it was precisely because of these "ethical, privacy and informed consent considerations regarding genetic testing of minors for predisposition or carrier status of adult-onset genetic disorders" [30] that Navigenics decided not to process samples or information from children who have not reached the age of majority.

The Human Genetics Commission (HGC) also raised the issue that any genetic testing service "that requires a sample to be collected at home or to be tested by the consumer at home runs the risk of samples being submitted for testing without proper consent" [31]. Therefore, it recommended that companies elaborate mechanisms to prevent non-consensual testing. During focus groups undertaken in preparation of the HGC report, particular concern was raised about how a company would be able to verify that a subject had consented to the test [32]. The HGC also supports the recommendations of the Advisory Committee on Genetic Testing's Code of Practice (1997) [33] which promotes the practice of not supplying genetic testing services direct-to-the-public to those under the age of 16 or to those not able to make a competent decision regarding testing. 
The sale of clinically unvalidated genetic tests, as is done by many companies whom acknowledge this, to adults is controversial. It becomes more controversial when these tests are being sold to adolescents or minors who are not able to decide for themselves. Companies that are selling clinically validated tests should adhere to all professional standards and guidelines and should be offering the same quality of services as someone would expected in a centre for clinical genetics.

Finally, it is interesting, yet perhaps not completely unexpected, that while some companies' websites do not explicitly elaborate a policy about whether or not they test children upon parental request, they do take the time to explain to whom their website is directed or not directed. Cygene's website, for example, clearly states that "You should also be aware that this website is not intended for, or designed to attract, individuals under the age of 18." DNA Direct underlines that their services are not "designed or intended to attract children under the age of 13." The age of 13 can be explained by the fact that in the USA specific regulations (i.e. the Children's Online Privacy Protection Act) and guidelines (i.e. CARU guidelines for interactive media) apply to advertisements that are directed to children under the age of 13.

Finally, it is clear that our web-based method of analysis poses limitations to knowing what companies are really doing when faced with a request to test a child. This is true for all companies, regardless of the categories in which they have been classified. Furthermore, simply because a company's website does not include any information regarding testing in minors, this does not necessarily exclude the possibility that they do have a sound policy. In this regard, further research is necessary in which companies are directly approached in order to collect data regarding the number of tests they actually perform on children, and to compare if the position found on their webiste fully reflects what is done in practice. Moreover, the fact that this article only focuses on DTC genetic testing in children does not imply that there are no concerns regarding testing in adults. As was briefly mentioned in the introduction, this type of DTC service has raised a number of questions and concerns regarding many aspects of testing, including the clinical validity and utility of the tests.

\section{Conclusion}

We have analyzed the websites of 29 companies which sell health-related genetic tests directly to consumers. Many of these companies have not integrated a clear policy on their website regarding whether or not they would process samples coming from minors. It would be responsible for, at least, the companies selling genetic tests also offered in a clinical setting, to consider how to incorporate standards established by professional guidelines. This being said, even for genetic tests that are described as 'not being services which should be used to make medical decisions', the same best interest considerations, respect for autonomy, confidentiality and privacy suggest that children should not be tested unless there are immediate benefit for the child.

Acknowledgments $\mathrm{PB}$ is funded by the Research Fund Flanders and $\mathrm{HCH}$ is funded by an International Incoming Marie Curie Fellowship (European Commission).

\section{References}

1. Borry P, Stultiens L, Nys H, Cassiman JJ, Dierickx K (2006) Presymptomatic and predictive genetic testing in minors: a systematic review of guidelines and position papers. Clin Genet 70(5):374-381. doi:10.1111/j.1399-0004.2006.00692.x

2. Suter SM (1993) Whose genes are these anyway?: familial conflicts over access to genetic information. Mich Law Rev 91(7):1854-1908. doi:10.2307/1289655

3. British Medical Association (2001) Consent, rights and choices in health care for children and young people. BMJ Books, London

4. Fanos JH (1997) Developmental tasks of childhood and adolescence: implications for genetic testing. Am J Med Genet 71(1):22-28. doi:10.1002/(SICI)1096-8628(19970711)71:1<22:: AID-AJMG4>3.0.CO;2-S

5. Group ETC (2008) Direct-to-consumer DNA Testing and the myth of Personalized Medicine: Spit Kits, SNP Chips and Human Genomics. 2008. www.etcgroup.org

6. Mykitiuk R (2004) Caveat emptor: direct-to-consumer supply and advertising of genetic testing. Clin Invest Med 27(1):23-32

7. Cook L (2007) Should we all be testing our DNA? BBC 5 Live Report

8. Janssens AC, Gwinn M, Bradley LA, Oostra BA, van Duijn CM, Khoury MJ (2008) A critical appraisal of the scientific basis of commercial genomic profiles used to assess health risks and personalize health interventions. Am J Hum Genet 82(3):593599. doi:10.1016/j.ajhg.2007.12.020

9. Wade CH, Wilfond BS (2006) Ethical and clinical practice considerations for genetic counselors related to direct-to-consumer marketing of genetic tests. Am J Med Genet C Semin Med Genet 142(4):284-292. doi:10.1002/ajmg.c.30110

10. Schmidt C (2008) Regulators weigh risks of consumer genetic tests. Nat Biotechnol 26(2):145-146. doi:10.1038/nbt0208-145

11. Katsanis SH, Javitt G, Hudson K (2008) Public health. A case study of personalized medicine. Science 320(5872):53-54. doi: 10.1126/science. 1156604

12. Borry P, Howard HC, Sénécal K, Avard D (2009) Direct-toconsumer genome scanning services. Also for children? Nat Rev Genet 10(1):8

13. Genetics and Public Policy Center (2008) Center receives NIH award to study direct-to-consumer genetic testing. http://www. dnapolicy.org/news.release.php?action=detail\&pressrelease_id= 107

14. German Society of Human Genetics (1995) Statement on genetic diagnosis in children and adolescents. http://www.gfhev.de/en/ gfh/

15. Danish Council of Ethics (2001) Genetic investigation of healthy subjects-report on presymptomatic gene diagnosis. http://www. etiskraad.dk/sw293.asp 
16. European Society of Human Genetics (2001) Provision of genetic services in Europe-current practices and issues. www.eshg.org

17. Bioethics Committee Canadian Paediatric Society (2003) Guidelines for genetic testing of healthy children. Paediatr Child Health 8(1):42-45

18. European Society of Human Genetics (2009) Genetic testing in asymptomatic minors: recommendations of the European Society of Human Genetics. Eur J Hum Genet 17(6):720-721

19. Direct DNA our standards. http://www.dnadirect.com/web/ about_dna_direct/dna-direct-standards Accessed 10/01/2009

20. The American Society of Human Genetics Board of Directors, The American College of Medical Genetics Board of Directors (1995) Points to consider: ethical, legal, and psychological implications of genetic testing in children and adolescents. Am J Hum Genet 57:1233-1241

21. National Society of Genetic Counselors (1995) Position satement on prenatal and childhood testing for adult-onset disorders. http://www.nsgc.org/about/position.cfm\#Prenatal_two

22. Consumer Genetics Authorization and Disclosure form. http:// www.consumergenetics.com/pdfs/Asthma-Brochure.pdf. Accessed 10 January 2009

23. iGenix (2009) Privacy policy. http://www.qtrait.com/privacy_ policy. Accessed 10 January

24. 23andme (2009) Terms of Service. https://www.23andme.com/ about/tos/. Accessed 10 January
25. Gollust SE, Hull SC, Wilfond BS (2002) Limitations of directto-consumer advertising for clinical genetic testing. JAMA 288(14):1762-1767. doi:10.1001/jama.288.14.1762

26. Lupton D (2001) Risk as moral danger: the social and political functions of risk discourse in public health. In: Conrad P (ed) The sociology of health and illness. Worth Publishers, New York, pp 394-403

27. Grob R (2008) Is my sick child healthy? Is my healthy child sick?: changing parental experiences of cystic fibrosis in the age of expanded newborn screening. Soc Sci Med 67(7):1056-1064. doi:10.1016/j.socscimed.2008.06.003

28. SeqWright Privacy Policy (2008) http://www.seqwright.com/gps/ privacy.php. Accessed 20 October

29. Decode (2009) The deCODEme concept. http://www.decodeme. com/index/about_concept. Accessed 10 January

30. Navigenics (2009) Privacy Policy. 2009. http://www.navigenics. com/policies/Privacy/. Accessed 10 January

31. Human Genetics Commission Genes Direct (2003) Ensuring the effective oversight of genetic tests supplied directly to the public. http://www.hgc.gov.uk

32. People, Science and Policy Ltd (2002) The supply of genetic tests direct to the public: supporting the public consultation. 9-5-0008

33. Advisory Committee on Genetic Testing (1997) Code of practice and guidance on human genetic testing services supplied direct to the public. London, Health Departments of the United Kingdom 